\title{
The antibacterial effect of the combination of red raspberry concentrate and antibiotics on Staphylococcus aureus
}

\author{
Aleksandar Bokan ${ }^{1 *}$, Saša Vukmirović ${ }^{1,2}$, Deana Medić ${ }^{1,3}$ \\ From 4th International Conference for Healthcare and Medical Students (ICHAMS) 2014 \\ Dublin, Ireland. 24-25 October 2014
}

\section{Background}

The increasing presence of both methicillin-resistant isolates of Staphylococcus aureus (MRSA), and lately vancomycin-resistant Staphylococcus aureus (VRSA), requires pursuit of new antibiotics. This is achieved in several ways: by modification of existing antibiotics, by synthesis of new antibiotics or by empirical screening of, so far, unexamined compounds. Consumption of fresh or processed berries (raspberry, blackberry, strawberry, currant, cranberry and other berries) is considered exceptionally beneficial due to the potent antioxidant and antibacterial activity of their phenolic compounds. Having in mind high percentage of highly resistant bacterial strains of Staphylococcus aureus and antibacterial potency of red raspberries' phenolic compounds, the goal of study was to investigate interactive effect of red raspberries' concentrate and antibiotics on Staphylococcus aureus [1-4].

\section{Methods}

In the experiment we used: 1) absolute physicochemically unchanged, $100 \%$ natural raspberry juice, 2) clinical isolate of Staphylococcus aureus, 3) antibiotic discs for examination of bacterial susceptibility, 4) sterile $0.9 \%$ sodiumchloride and 5) Müller-Hinton agar. Testing the existence and type of interaction between the red raspberries' concentrate and the antimicrobial drugs was performed in vitro using Kirby-Bauer disc diffusion method in accordance with CLSI guidelines.

\section{Results}

The results of our study clearly indicate the existence of synergism between penicillin, cefoxitin, tetracycline, ciprofloxacin and fusidic acid with red raspberries' concentrate as the source of various phenolic compounds.

\section{Conclusions}

New classes of antibiotics are extremely necessary and flavonoids represent a potentially new group of antimicrobial substances that could potentiate the activity of conventional antibiotics.

\section{Authors' details}

'University of Novi Sad, Faculty of Medicine Novi Sad, Hajduk Veljkova 3, Novi Sad 21000, Republic of Serbia. Institute of pharmacology, Toxicology and Clinic Pharmacology, Hajduk Veljkova 3, Novi Sad 21000, Republic of Serbia. ${ }^{3}$ Institute of Public Health of Vojvodina, Center for Microbiology, Futoska 121, Novi Sad 21000, Republic of Serbia.

\section{Published: 27 October 2015}

\section{References}

1. Gould IM: VRSA-doomsday superbug or damp squib? Lancet Infect Dis 2010, 10(12):816-8.

2. Alcaráz LE, Blanco SE, Puig ON, Tomás F, Ferretti FH: Antibacterial activity of flavonoids against methicillin-resistant Staphylococcus aureus strains. J Theor Biol 2000, 205(2):231-40.

3. Puupponen-Pimiä R, Nohynek L, Alakomi HL, Oksman-Caldentey KM: Bioactive berry compounds-novel tools against human pathogens. Appl Microbiol Biotechnol 2005, 67(1):8-18.

4. Iwashina T: The structure and distribution of the flavonoids in plants. J. Plant Res 2000, 113:287-99.

doi:10.1186/1753-6561-9-S7-A1

Cite this article as: Bokan et al:: The antibacterial effect of the combination of red raspberry concentrate and antibiotics on Staphylococcus aureus. BMC Proceedings 2015 9(Suppl 7):A1. 